\title{
Micromechanical modelling of reversible and irreversible thermo-mechanical deformation of oriented polyethylene terephthalate
}

\section{Citation for published version (APA):}

Poluektov, M., Dommelen, van, J. A. W., Govaert, L. E., \& Geers, M. G. D. (2015). Micromechanical modelling of reversible and irreversible thermo-mechanical deformation of oriented polyethylene terephthalate. Computational Materials Science, 98, 189-200. https://doi.org/10.1016/j.commatsci.2014.11.004

DOI:

10.1016/j.commatsci.2014.11.004

Document status and date:

Published: 01/01/2015

Document Version:

Publisher's PDF, also known as Version of Record (includes final page, issue and volume numbers)

\section{Please check the document version of this publication:}

- A submitted manuscript is the version of the article upon submission and before peer-review. There can be important differences between the submitted version and the official published version of record. People interested in the research are advised to contact the author for the final version of the publication, or visit the DOI to the publisher's website.

- The final author version and the galley proof are versions of the publication after peer review.

- The final published version features the final layout of the paper including the volume, issue and page numbers.

Link to publication

\footnotetext{
General rights

- You may freely distribute the URL identifying the publication in the public portal. follow below link for the End User Agreement:

www.tue.nl/taverne

\section{Take down policy}

If you believe that this document breaches copyright please contact us at:

openaccess@tue.nl

providing details and we will investigate your claim.
}

Copyright and moral rights for the publications made accessible in the public portal are retained by the authors and/or other copyright owners and it is a condition of accessing publications that users recognise and abide by the legal requirements associated with these rights.

- Users may download and print one copy of any publication from the public portal for the purpose of private study or research.

- You may not further distribute the material or use it for any profit-making activity or commercial gain

If the publication is distributed under the terms of Article $25 \mathrm{fa}$ of the Dutch Copyright Act, indicated by the "Taverne" license above, please 


\title{
Micromechanical modelling of reversible and irreversible thermo-mechanical deformation of oriented polyethylene terephthalate
}

\author{
M. Poluektov ${ }^{\mathrm{a}, \mathrm{b}}$, J.A.W. van Dommelen ${ }^{\mathrm{b}, *}$, L.E. Govaert ${ }^{\mathrm{b}}$, M.G.D. Geers ${ }^{\mathrm{b}}$ \\ a Materials innovation institute (M2i), P.O. Box 5008, 2600 GA Delft, The Netherlands \\ ${ }^{\mathrm{b}}$ Eindhoven University of Technology, P.O. Box 513, 5600 MB Eindhoven, The Netherlands
}

\section{A R T I C L E I N F O}

\section{Article history:}

Received 19 August 2014

Received in revised form 3 November 2014

Accepted 4 November 2014

\section{Keywords:}

Semi-crystalline polymers

Micromechanics

Oriented film

Thermal shrinkage

\begin{abstract}
A B S T R A C T
In this article, the reversible and irreversible thermo-mechanical time-dependent deformation of oriented polyethylene terephthalate film is studied. A mean-field model is used to simulate these effects along with the long-term creep behaviour, taking into account the underlying material microstructure and differences in constitutive behaviour of the phases. The material is modelled as an aggregate of layered two-phase domains. Irreversible deformation, or partial shape recovery, results from the presence of an internal stress, which is characterised and incorporated into the constitutive behaviour of the noncrystalline phase. Using the micromechanical approach, the deformation mechanisms at the local scale are analysed.
\end{abstract}

(c) 2014 Elsevier B.V. All rights reserved.

\section{Introduction}

Predictable mechanical response and high dimensional stability are major requirements for polymer substrates used in the production of flexible electronics $[1,2]$. There are a number of candidates for the substrate material with the most common materials being semicrystalline, oriented and thermally stabilised polyethylene terephthalate (PET) and polyethylene naphthalate (PEN) films. The goal of this work is to predict the dimensional stability of the polymer film at temperatures above the glass transition temperature, i.e. to simulate reversible and irreversible deformation of the film under these industrially relevant conditions based on the underlying microstructural information.

The polymer films studied here are produced by sequential biaxial stretching at temperatures above the glass transition $\left(T_{\mathrm{g}}\right)$ and subsequent cooling down to room temperature [3]. Upon heating above $T_{\mathrm{g}}$ these films demonstrate irreversible deformation under stress-free conditions, referred to as thermal shrinkage, or an emergence of shrinkage stress if the dimensions are fixed [4-6]. This process is significantly influenced by the manufacturing conditions [7]. Such behaviour can be classified as a shape-memory effect, where the partial recovery of the original shape is a result of increased molecular mobility above $T_{\mathrm{g}}$ and the driving force is due to the tendency of the structure to increase its entropy by relaxing the oriented conformation [8]. In oriented amorphous PET there is

\footnotetext{
* Corresponding author.

E-mail address: J.A.W.v.Dommelen@tue.nl (J.A.W. van Dommelen).
}

evidence that the molecular origin of this process lies in a redistribution of the rotational isomers along the polymer chains, leading to their coiling [9].

The modelling approaches of shape-memory polymers can roughly be divided into macroscopic and micromechanical $[8,10]$. In macroscopic models, the material behaviour is simulated as the behaviour of a system constructed of elastic, viscous and purely plastic elements. In this case, a nonlinear temperature-dependent viscosity captures the shape memory effect. In contrast, micromechanical approaches take into account aspects of the material microstructure, while often lacking some reliable experimental data at that fine scale. In [11], the material was considered to consist of active and frozen phases with the phase transition being described by a temperature dependent volume fraction. A similar approach was used in [12] to construct a large deformation model based on the rules of mixtures. In [13], a model for semicrystalline shape-memory polymers was presented, where the shape-memory effect occurred due to a tendency of each phase to return to its initial configuration.

In this article, the effect of shape recovery of a PET film is modelled using a micromechanical model referred to as the composite inclusion model [14-18]. In this model, the material is considered to consist of two phases: the crystalline and the amorphous phases, out of which layered domains are constructed. Here, the amorphous phase is referred to as non-crystalline since it significantly differs from purely amorphous material due to the constraints induced by crystalline lamellae and the presence of tie molecules. The material behaviour is modelled as the behaviour of an 
aggregate of such layered domains. Crystal plasticity [19] is used as a constitutive model for the crystalline phase, with viscous slip on the (limited number of) slip systems. The non-crystalline phase can be modelled with one of the material models suitable for glassy polymers, such as the model by Buckley et al. [20,21], by Boyce et al. [22,23] and by Govaert et al. [24,25]. In this article, the model by Govaert et al., referred to as the EGP model, is used.

In [26], the composite inclusion model was used to describe the deformation kinetics of oriented HDPE. However, the model was found to lack the contribution of the pre-stretched amorphous phase. In [18], this model was used to simulate short-term and long-term behaviour of the oriented PET film taking into account this pre-orientation. In the present article, the constitutive models of the phases are further extended, i.e. thermal expansion is added to the model and a relaxation of the internal pre-stress state of the PET film is incorporated to simulate the behaviour of the film at high temperatures and to model reversible and irreversible thermal deformation. The aim of this article is to simulate these effects based on the underlying microstructure, and therefore to obtain a reliable structure-property relationship and to analyse microstructural deformation processes.

\section{Experimental methods}

Thermally stabilised oriented polyethylene terephthalate film, manufactured by DuPont Teijin Films, was provided for the experimental analysis. The film is produced by sequential biaxial stretching with draw ratios 3.1 and 3.4 in machine direction (MD) and transverse direction (TD) respectively. The draw temperature in the first (MD) stage was set to $90^{\circ} \mathrm{C}$, and the TD draw temperature was set to $110^{\circ} \mathrm{C}$. The MD stretch stage is at a "constant width", and when heated, the film is accelerated between two rotating rollers which causes the material to stretch to a fixed ratio. The TD draw was performed in a "stenter oven", where each edge of the film was clamped to a continuously moving chain. By causing the path of the two chains to diverge, the edges of the film were continuously drawn apart. The temperature during the final heat set was set to $210^{\circ} \mathrm{C}$. The manufactured film had an average thickness of $125 \mu \mathrm{m}$, a width of $90 \mathrm{~cm}$ and an approximate crystallinity of $50 \%$.

To measure irreversible deformation of the film resulting from different heating conditions, the behaviour of oriented PET film was measured using two different techniques. Strain measurements at varying temperatures were performed under uniaxial tensile stress-controlled conditions using a Zwick Z010 universal tensile tester equipped with a video extensometer, a temperature controlled chamber and a $1 \mathrm{kN}$ force cell. Samples, with a shape according to ISO 527-2, type 1BA, cut in different directions were heated from $60{ }^{\circ} \mathrm{C}$ to $190^{\circ} \mathrm{C}$ with subsequent annealing at $190{ }^{\circ} \mathrm{C}$. Three heating rates were imposed: constant rates of $1{ }^{\circ} \mathrm{C} / \mathrm{min}, 5^{\circ} \mathrm{C} / \mathrm{min}$ and $\sim 10^{\circ} \mathrm{C} / \mathrm{min}$, which is the maximum heating rate of the temperature controlled chamber. Measurements were performed under imposed stress of $0.16 \mathrm{MPa}$, which is sufficient to keep the sample straight while not leading to noticeable creep effects at high temperatures. Prior to testing, the samples were dried in the temperature controlled chamber at $60{ }^{\circ} \mathrm{C}$ for $60 \mathrm{~min}$ to prevent interference of dehydration-induced contraction with the measurements. For the samples heated at $10{ }^{\circ} \mathrm{C} / \mathrm{min}$ and $5{ }^{\circ} \mathrm{C} / \mathrm{min}$, multiple measurements were performed to ensure reproducibility.

The residual (i.e. irreversible) deformation after cooling down was measured using digital image correlation (DIC). Dried samples with dimensions of $15 \mathrm{~cm}$ by $10 \mathrm{~cm}$ (in TD and MD, respectively) with a grid of $16 \times 11$ dots were placed in a pre-heated oven and annealed for a certain time. Images of samples (with the size of
$3300 \times 2200 \mathrm{px}$ ) were taken before the heat treatment and after removing the sample from the oven and cooling it down to room temperature, thus eliminating reversible thermal deformation (thermal expansion). The two-dimensional strain was extracted from the images by correlating the displacement of the dots across the series of images. A uniform strain field in each sample was assumed, since the strain inhomogeneity within one sample was of the same order of magnitude as the deviation of the average strain within multiple samples tested at identical conditions. The actual calculated strain in each sample tested at certain conditions was averaged from three subsequently taken images. Since heating and annealing of the samples was performed at stress-free conditions, film wrinkling, resulting from inhomogeneity of the sample and of the temperature field, was observed. Therefore, when images of the samples were recorded, the samples were straightened by putting a glass plate on top.

The anisotropy and inhomogeneity of the film was studied in [18]. It was found that for the centre of the film (i.e. the middle position across the width) the principal strain directions correspond to MD and TD and for the sides the principal directions are rotated by $15^{\circ}$. Therefore the effective MD and TD, which are rotated by a small angle, are introduced here for the right part of the film. In [18], the mechanical behaviour along the effective directions was found to be similar across the width of the film. Therefore, here samples from the sides of the film were also used for the experimental programme with strain measurements performed along the effective machine and transverse directions.

To measure the coefficient of thermal expansion (CTE) of isotropic PET, semicrystalline PET samples were prepared from isotropic amorphous PET, which was also supplied by DuPont Teijin Films, by annealing in an oven for $1,4,10$ and $13 \mathrm{~h}$ at $100^{\circ} \mathrm{C}$. Crystallinity of the samples was measured by X-ray diffraction and DSC. To determine the CTE, PET samples were heated from $30^{\circ} \mathrm{C}$ to $70^{\circ} \mathrm{C}$ and then cooled down to $30^{\circ} \mathrm{C}$ at a rate of $5{ }^{\circ} \mathrm{C} / \mathrm{min}$. The cycle was repeated 2 times, and the obtained measurements of the CTE during heating and cooling were averaged. The deformation field was obtained by DIC. The observed deformation of the samples was homogeneous and linearly dependent on temperature within the imposed temperature region.

The CTE of the oriented PET film was measured using the same technique as used to measure the CTE of isotropic PET, however during the heating stage of the first cycle, strain was not recorded, and thus only 3 measurements ( 2 during cooling and 1 during heating) were taken. Measurements on 3 samples from the centre of the film were performed and the results were averaged.

\section{Measurements, oriented material}

The thermomechanical behaviour of PET film under different conditions was studied. The imposed temperature profile is

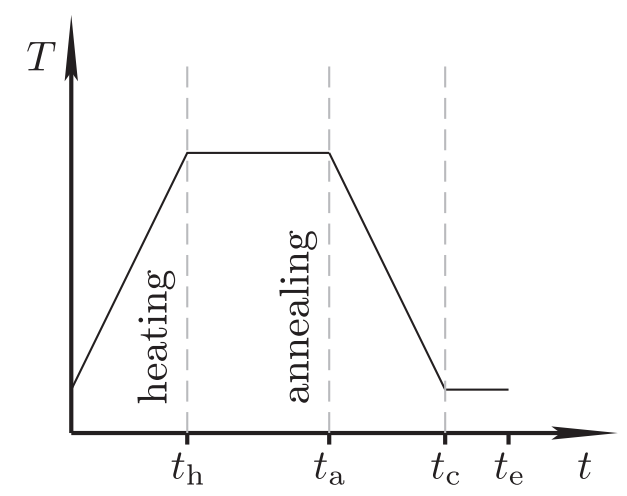

Fig. 1. Schematic representation of the imposed temperature profile. 
illustrated in Fig. 1. In the first case, the strain evolution during only the "heating" and "annealing" stages is considered with an imposed heating rate of $1-10^{\circ} \mathrm{C} / \mathrm{min}$. In the second case, only irreversible deformation due to the imposed temperature history is considered, i.e. only the strain value at $t=t_{\mathrm{e}}$ and its dependence on parameters of the temperature profile (the annealing temperature and the annealing time). As described in Section 2, for the second case, samples were placed in a preheated oven, which resulted in almost instantaneous heating of the samples to the annealing temperature (in Section 5.2, to model this case a heating rate of $17{ }^{\circ} \mathrm{C} / \mathrm{s}$ was used).

The heating stage and the annealing stage of the strain measurements are analysed separately. Measurements corresponding to a particular heating rate were reproducible with the absolute strain deviation between several samples not exceeding $2.5 \cdot 10^{-3}$. In Fig. 2, the effect of heating rate on the measured strain is demonstrated. It is obvious that the deformation due to heating is anisotropic with TD expanding and MD shrinking at lower temperatures. At higher temperatures, TD also shows shrinkage with a faster deformation rate than for MD. Although for TD samples, the influence of the heating rate on strain is comparable to experimental scatter, for MD it is noticeably larger. Using this measuring method, only combined reversible and irreversible deformations are obtained.

To analyse only irreversible deformations, the permanent strain resulting from fast heating of the sample in the oven was obtained with digital image correlation after cooling the sample. The influence of annealing temperature and annealing time was investigated. In Fig. 3, the measured strain and its dependence on annealing time (the time-dependent nature of the thermal irreversible deformation) and annealing temperature for the samples in effective MD and TD is shown. Comparing Figs. 2 and 3, it can again be seen that the heating rate influences the residual shrinkage strain with approximately doubled strain values for the case when samples are placed in a preheated oven. The reason for this is internal relaxation taking place in the material during slow heating, which does not lead to a macroscopic deformation, as well as the absence of reversible thermal deformation (thermal expansion) in the results shown in Fig. 3.

The maximum absolute value of the deviation of the shear strain from zero is $3 \cdot 10^{-3}$, i.e. the principal directions of the strain tensor deviate only slightly from the previously measured $15^{\circ}$ at the sides of the film. This small deviation changes with annealing temperature: the shear strain is positive for temperatures below $180^{\circ} \mathrm{C}$ and negative above this value.

\section{Micromechanical modelling}

The material behaviour is modelled at multiple scales using the composite inclusion model, see [16,27]. A detailed model description can be found in Appendices A-C. The macroscopic scale corresponds to a material point, where the Cauchy stress tensor $\boldsymbol{\sigma}^{\mathrm{M}}$ and the deformation gradient tensor $\boldsymbol{F}^{\mathrm{M}}$ are volume averaged quantities of the two-phase layered microstructure, which consists of multiple differently oriented layered domains, each consisting of different phases, see Fig. 4. The two-phase domains are referred to as composite inclusions [15]. Each phase in a domain is described with its representative constitutive law and has homogeneous stress and deformation fields. Compatibility and equilibrium conditions are enforced at the interface between the phases:

$$
\sigma_{n 3}^{c k}=\sigma_{n 3}^{\mathrm{a} k} ; \quad F_{n s}^{c k}=F_{n s}^{\mathrm{a} k} ; \quad k=\overline{1, N} ; \quad n=\{1,2,3\} ; \quad s=\{1,2\},
$$
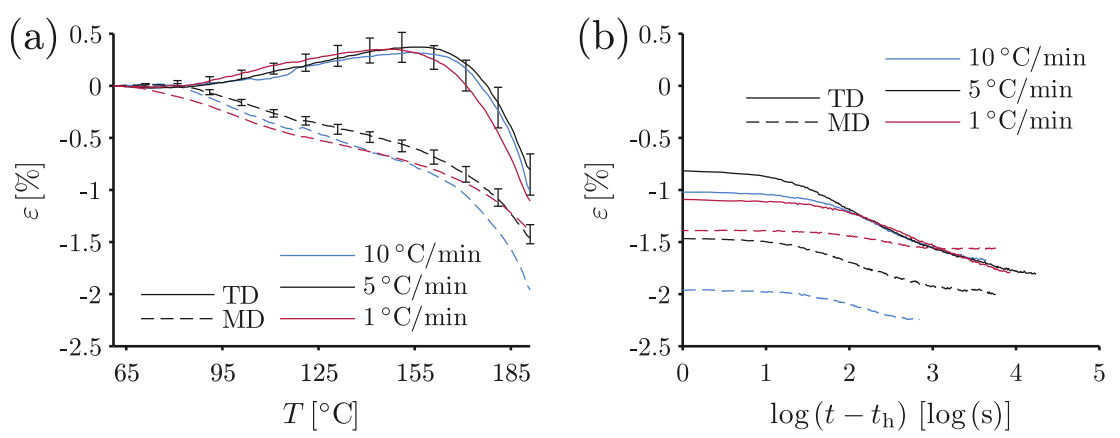

Fig. 2. Dependence of strain on temperature for $M D$ and TD samples during heating at heating rates of $1-10^{\circ} \mathrm{C} / \mathrm{min}$ (a) and evolution of strain with time during annealing at $190{ }^{\circ} \mathrm{C}$ starting from the point of reaching the annealing temperature (b). For the heating rate of $5{ }^{\circ} \mathrm{C} / \mathrm{min}$, error bars indicating a $95 \%$ confidence interval are shown, where experimental scatter results from 9 measurements per direction (MD and TD).
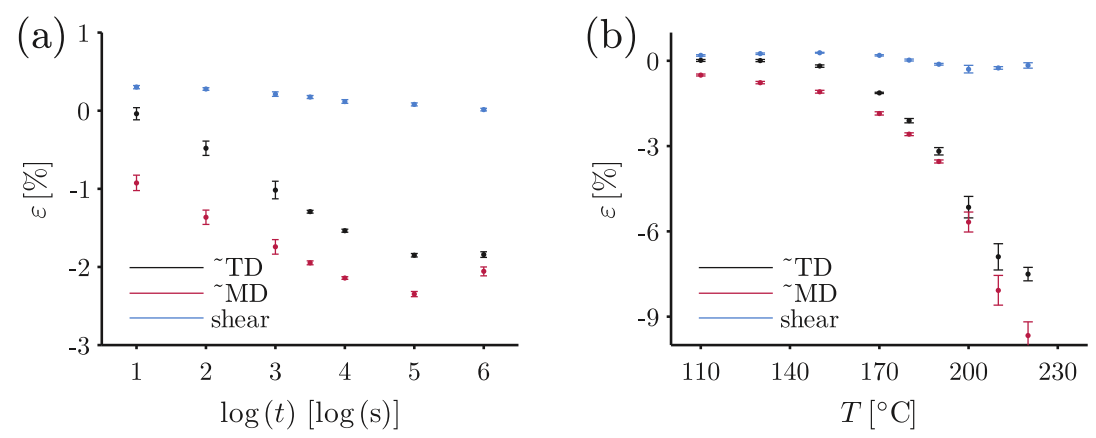

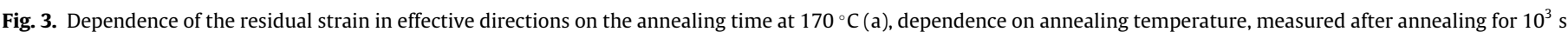

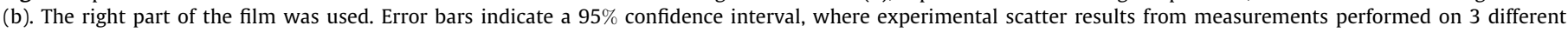
samples and 3 images taken per sample per measurement. 


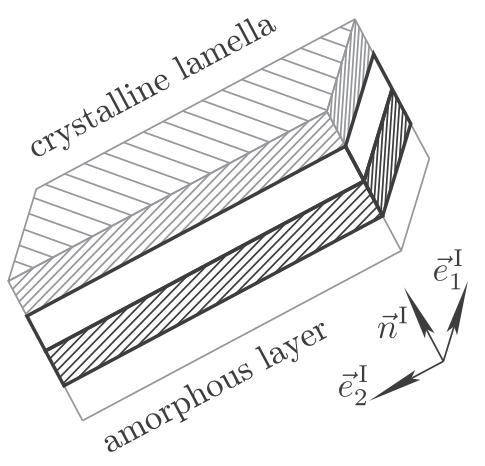

Fig. 4. The two-layer composite inclusion after $[15,16]$. The structural unit of the model is highlighted in a stack of crystalline lamellae.

where components are taken with respect to the inclusion coordinate system shown in Fig. 4 (with unit vectors $\vec{e}_{1}^{\mathrm{I}}, \vec{e}_{2}^{\mathrm{I}}$, $\vec{e}_{3}^{1}=\vec{n}^{\mathrm{l}}$ ). Superscripts "c", "a" indicate quantities belonging to crystalline and non-crystalline phases and $N$ is the number of layered domains. The average stress tensor $\boldsymbol{\sigma}^{\mathrm{l}}$ and deformation gradient tensor $\boldsymbol{F}^{\mathrm{I}}$ of each layered domain are obtained by volume averaging. The domains are coupled using a mean-field interaction law $[15,16]$ : the components of the inclusion-averaged stress and deformation gradient tensors that are not constrained by intra-inclusion equilibrium and compatibility conditions, are equal to their corresponding macroscopic quantities. Macroscopic quantities $\boldsymbol{F}^{\mathrm{M}}$ and $\boldsymbol{\sigma}^{\mathrm{M}}$ are obtained by volume averaging the inclusion-averaged quantities $\boldsymbol{\sigma}^{\mathrm{I}}$ and $\boldsymbol{F}^{\mathrm{I}}$. The semicrystalline morphology is then characterised by the orientation distribution of the crystalline phases and interfaces between the crystalline and the non-crystalline phase.

Here, simulations of isotropic and oriented material are performed. The difference in model behaviour results from the orientation differences of the layered domains, which is illustrated in the equal area projection pole figures in Fig. 5, where the crystal orientations as well as the orientations of interface normals are shown. For the isotropic material, a set of uniform random orientations is adopted. For the oriented material, the orientation distribution in the PET film was characterised in [18]. For the isotropic case 125 inclusions were used, and for the oriented case 100 inclusions were used (based on a convergence study performed in [18]). Another difference is the incorporation of anisotropic internal stresses in the non-crystalline phase for the oriented material, whereas a stress-free non-crystalline phase is used for the isotropic material, as further elaborated in the following section. This addition was required to accurately model the differences between the long-term creep responses in MD and TD directions [18].

\subsection{Constitutive behaviour of the phases}

A multiplicative decomposition of the deformation gradient tensor into an elastic (e), thermal ( $\mathrm{t}$ ) and plastic (p) part is used for both phases: $\boldsymbol{F}=\boldsymbol{F}_{\mathrm{e}} \cdot \boldsymbol{F}_{\mathrm{t}} \cdot \boldsymbol{F}_{\mathrm{p}}$ [28]. Thermal expansion was introduced for each phase, with anisotropic expansion for the crystalline phase and isotropic expansion for the non-crystalline phase. The thermal velocity gradient is linearly dependent on the time derivative of the temperature through a tensor $\boldsymbol{\alpha}^{v}$ containing thermal expansion coefficients:

$\boldsymbol{L}_{\mathrm{t}}^{v}=\dot{\boldsymbol{F}}_{\mathrm{t}}^{v} \cdot \boldsymbol{F}_{\mathrm{t}}^{v-1}=\boldsymbol{\alpha}^{v} \dot{T} ; \quad v=\mathrm{a}, \mathrm{c}$

The non-crystalline phase is modelled with the Eindhoven Glassy Polymer (EGP) model [29,25,30], which consists of a combination of viscoelastic Maxwell elements with neo-Hookean-like elasticity and non-linear viscosity, which is temperature and stress dependent. This constitutive model is schematically illustrated in Fig. 6(a), where for simplicity only two viscoelastic modes are illustrated. The stress dependency is described using the Eyring flow model and temperature dependency using the Arrhenius law. The viscosity depends on the equivalent stress $\tau$, the pressure $p^{\text {a }}$, the temperature $T$ and the thermomechanical history $S$ :

$\eta_{i}=\eta_{0 \text { ir }} \exp \left(\frac{\Delta U}{R}\left(\frac{1}{T}-\frac{1}{T_{\mathrm{r}}}\right)\right) \frac{\tau / \tau_{0}}{\sinh \left(\tau / \tau_{0}\right)} \exp \left(\frac{\mu p^{\mathrm{a}}}{\tau_{0}}\right) \exp (S) ;$

$\tau_{0}=\frac{k T}{V^{*}}$,

where $R$ is the universal gas constant, $\Delta U$ the activation energy, $T_{\mathrm{r}}$ a reference temperature, $k$ is the Boltzmann constant and $V^{*}$ the activation volume. Multiple molecular relaxation processes can be taken into account in this constitutive model by using different stress and temperature dependency parameters for viscoelastic
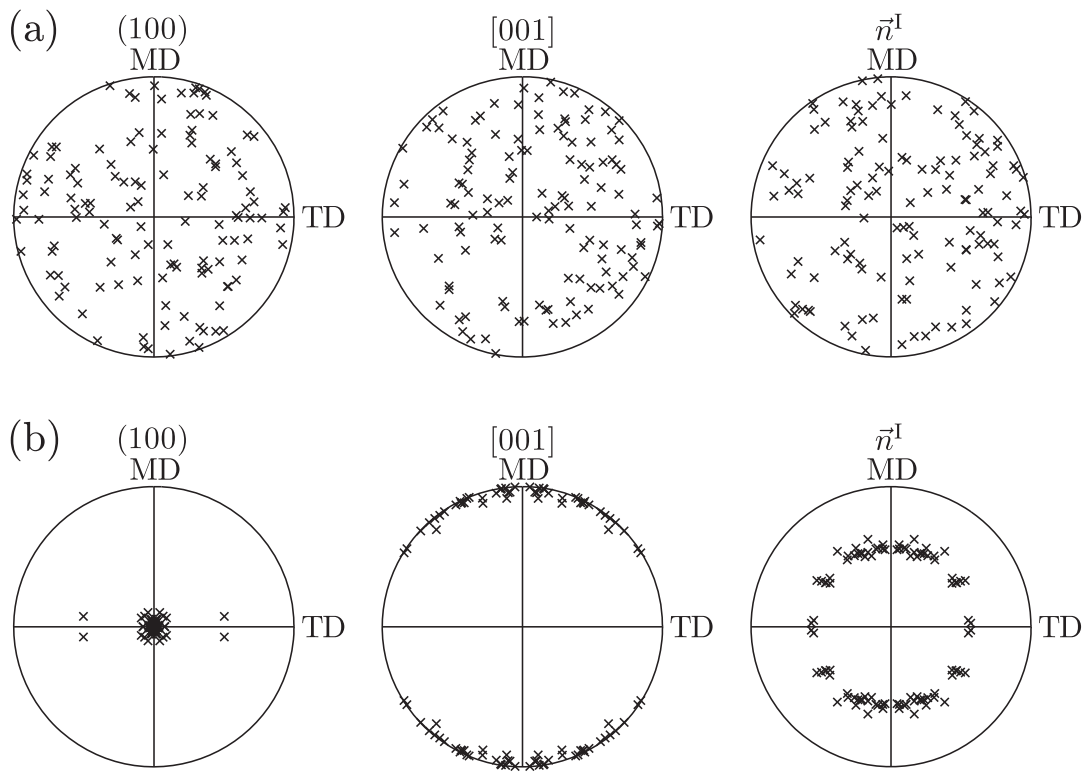

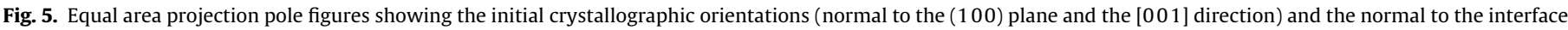
between phases $\left(\vec{n}^{I}\right)$ for isotropic material (a) and oriented material (b). The orientation set in (b) is taken from [18]. 
(a)

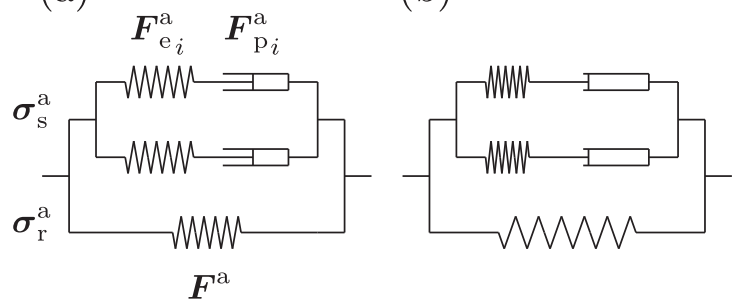

Fig. 6. Schematic representation of the constitutive models used for the noncrystalline phase. Original EGP model formulation (a) and model with a predeformed initial state used in [18] (b).

modes. This model in combination with the composite inclusion model described above was used to simulate the large-strain mechanical behaviour of isotropic semicrystalline PET [27]. To simulate the long-term and short-term behaviour of an oriented PET film [18], an internal pre-stress in the elastic elements describing the molecular network was included. These elastic elements are initially in a pre-deformed state (tension in MD and compression in TD), see Fig. 6(b), thus introducing anisotropic yielding of the viscoplastic elements with isotropic behaviour in the elastic regime. The deformation gradient tensor $\boldsymbol{F}_{\mathrm{r}}^{\mathrm{a}}$ corresponding to the molecular network is calculated from the total deformation gradient tensor $\boldsymbol{F}^{\mathrm{a}}$ of the non-crystalline phase:

$\boldsymbol{F}_{\mathrm{r}}^{\mathrm{a}}=\boldsymbol{F}^{\mathrm{a}} \cdot \boldsymbol{F}_{\mathrm{d}}^{\mathrm{a}}$

where $\boldsymbol{F}_{\mathrm{d}}^{\mathrm{a}}$ is a deformation gradient tensor determining the initial pre-deformation of the network. Initial elastic and plastic deformation gradients are calculated such that stress equilibrium of the non-crystalline phase is maintained initially, $\boldsymbol{\sigma}^{\mathrm{a}}(t=0)=\boldsymbol{0}$, whereby the deformation gradient tensor equals the identity tensor, i.e. $\boldsymbol{F}^{\mathrm{a}}(t=0)=\boldsymbol{I}$. The original formulation of the EGP model is recovered if $\boldsymbol{F}_{\mathrm{d}}^{\mathrm{a}}=\boldsymbol{I}$. This internal stress state, which was included in [18] to describe the anisotropic creep behaviour of oriented film, is the basic mechanism which causes irreversible thermal deformations (an in-plane pre-deformation was used in [18]). However, to describe dimensional stability at temperatures above $T_{\mathrm{g}}$, as required here, several additional modifications are made.

In Section 3, experimental results indicated that the heating rate influences residual irreversible deformation. This is included in the model by replacing the elastic hardening element in the EGP model by a viscoelastic element, see Fig. 7(a), with a temperature dependent viscosity:

$\eta_{\mathrm{r}}=\eta_{0 \mathrm{r}} \exp \left(\frac{\Delta U_{\mathrm{r}}}{R}\left(\frac{1}{T}-\frac{1}{T_{\mathrm{r}}}\right)\right)$

(a)

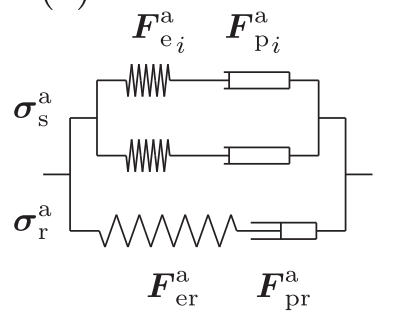

(b)

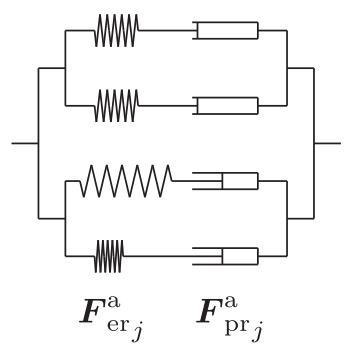

Fig. 7. Schematic representation of the constitutive models used for the noncrystalline phase. Model extended with internal relaxation of the hardening stress (a) and model further extended with anisotropic pre-deformation (b).
The molecular mobility of a part of the non-crystalline phase is strongly inhibited by the presence of the crystalline material, leading to a strong increase of the local $T_{\mathrm{g}}$. As a result, the temperature dependence of the viscosity of this "constrained amorphous phase" is taken Arrhenius-like, similar to that of a polymer glass. As such, a mechanism of stress relaxation during slow heating is incorporated, which leads to a lower irreversible shrinkage strain. A large relaxation time for the hardening elements is required such that these modes deform only elastically below $T_{\mathrm{g}}$.

The crystalline phase is modelled with crystal viscoplasticity [19], where the deformation is decomposed into elastic and viscoplastic parts in addition to the thermal expansion. The elastic behaviour of the crystalline phase is anisotropic. The viscoplastic deformation is a superposition of shear deformations on a limited number of crystallographic slip systems with an Eyring flow equation relating shear rate and resolved shear stress [17,27].

Since the mechanism of irreversible thermal deformation (deformation driven by the presence of internal stresses due to the pre-stretched non-crystalline phase) is incorporated in the non-crystalline phase only, it elastically loads the crystalline phase during and after thermal deformation. If the crystalline phase deforms only elastically, it can subsequently deform the non-crystalline phase over longer time scales, such that the absolute value of the residual shrinkage strain is decreasing, i.e. the material is returning to its initial configuration, which is not experimentally observed. Therefore, a thermal dependence of the plastic slip has to be incorporated to increase the mobility of slip systems (decrease the time scale of plastic deformation), enabling plastic deformations in the crystalline phase at high temperatures. The following relation between shear stress $\tau^{\alpha}$ and shear rate $\dot{\gamma}^{\alpha}$ on slip system $\alpha$ is used:

$\dot{\gamma}^{\alpha}=\xi^{\alpha} \exp \left(\frac{\Delta U^{\alpha}}{R}\left(\frac{1}{T_{\mathrm{r}}}-\frac{1}{T}\right)\right) \sinh \frac{\tau^{\alpha}}{\tau_{0}^{\alpha}}$

where $\Delta U^{\alpha}$ is the activation energy of the slip system, $T$ the current temperature and $T_{\mathrm{r}}$ a reference temperature. A similar dependence of crystallographic slip on temperature was also included in a micromechanical model of HDPE in [17].

The influence of viscoelastic hardening of the non-crystalline phase and thermal dependence of the slip kinetics on the macroscopic behaviour obtained with the composite inclusion model is shown in Fig. 8, where the evolution of strain with time after reaching $T=190{ }^{\circ} \mathrm{C}$ is simulated. The heating stage $\left(t<t_{\mathrm{h}}\right)$ is not shown here. A uniaxial state of pre-deformation of the non-crystalline phase (as in [18]) is imposed, with $\lambda_{d}=1.25$. Other model parameters are summarised in Appendix D. The following cases are compared:

1. non-crystalline phase with elastic hardening;

2. non-crystalline phase with internal relaxation of the hardening stress (with activation energy $\Delta U=225 \mathrm{~kJ} / \mathrm{mol}$ );

3. crystalline phase with temperature dependent slip systems (parameters as in Appendix D);

4. viscoelastic hardening and temperature dependent slip systems as in case (2) and (3), respectively.

The introduction of a temperature dependence of the slip systems significantly influences the deformation during annealing. Without allowing for relaxation of the internal hardening stresses of the non-crystalline phase, they drive the material to a state where the non-crystalline phase is stress-free, i.e. to a large strain determined by the pre-deformation. From a comparison of Figs. 2, 3 and 8 it can be seen that the simulated material behaviour is still not qualitatively matching the measurements. These observations 

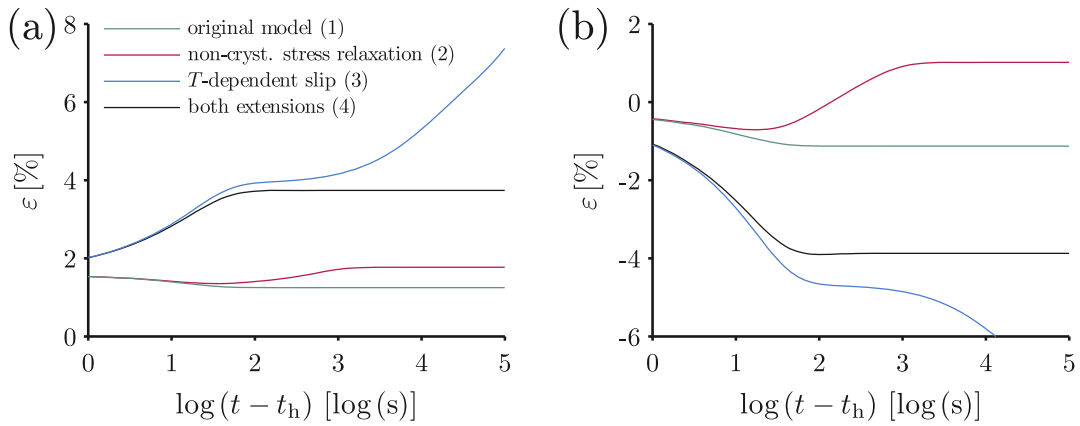

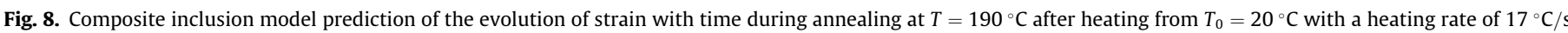

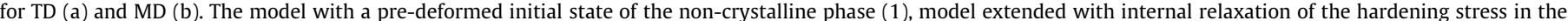
non-crystalline phase (2), extended with temperature dependent slip systems in the crystalline phase (3) and extended with both modifications of cases 2 and 3 (4).

indicate an anisotropic internal stress state, which constitutes the basis for further modifications.

Previously, it was shown that the non-crystalline phase of these films has a uniaxial internal stress state [18]. This was based on modelling the long-term behaviour of the film, in correspondence with the experimentally observed behaviour. In Section 3 it was shown that during heating to high temperatures, irreversible shrinkage deformation is observed in both directions, which indicates that at high temperatures the non-crystalline phase of the film demonstrates a biaxial internal stress state. At low temperatures, irreversible expansion in TD and irreversible shrinkage in MD were observed, indicating a uniaxial internal stress state at low temperatures. Therefore, to describe both effects, the viscoelastic hardening in the non-crystalline constitutive model was split into two modes with different activation energies and different pre-deformations:

$\boldsymbol{F}_{\mathrm{d} j}^{\mathrm{a}}=\lambda_{\mathrm{TD} j} \vec{e}_{1} \vec{e}_{1}+\lambda_{\mathrm{MD} j} \vec{e}_{2} \vec{e}_{2}+\frac{1}{\lambda_{\mathrm{TD} j} \lambda_{\mathrm{MD} j}} \vec{e}_{3} \vec{e}_{3}, \quad j=\overline{1, N^{\mathrm{r}}}$,

where $N^{\mathrm{r}}=2$ is the number of hardening modes, $\vec{e}_{1}$ corresponds to TD and $\vec{e}_{2}$ corresponds to MD. Pre-deformation ratios and activation energies for the hardening modes are summarised in Table 1. Hardening moduli for these modes are equal (the full set of model parameters is given in Appendix D). For the adopted parameter set, both modes deform elastically at low temperatures and jointly reveal a uniaxial stress state as in [18], allowing the simulation of anisotropic creep of the film. With increasing temperature, one of the modes undergoes relaxation while the other mode still contributes to the internal stress, thus describing a biaxial stress state leading to irreversible thermal shrinkage in both directions. This split is schematically illustrated in Fig. 7(b). Note that the figure represents only one-dimensional analogues of the model, whereas in the full 3D model, the hardening stress $\boldsymbol{\sigma}_{\mathrm{r}}^{\mathrm{a}}$ is anisotropic. Values of the activation energies were identified from the experimental data (Figs. 2 and 3). Results of simulations using this constitutive model for the non-crystalline phase are compared in Section 5.2.

\section{Results}

\subsection{Characterisation of thermal expansion}

The thermal expansion of the crystalline phase of PET is anisotropic due to the triclinic lattice structure of the PET unit cell, [31].

Table 1

Pre-deformation parameters of the non-crystalline phase for oriented PET film.

Parameter $\lambda_{\mathrm{TD}_{1}}(-) \lambda_{\mathrm{MD}_{1}}(-) \lambda_{\mathrm{TD}_{2}}(-) \lambda_{\mathrm{MD}_{2}}(-) \Delta U_{\mathrm{r}_{1}}(\mathrm{~kJ} / \mathrm{mol}) \Delta U_{\mathrm{r}_{2}}(\mathrm{~kJ} / \mathrm{mol})$

$\begin{array}{lllllll}\text { Value } & 1.37 & 0.93 & 0.39 & 1.74 & 225 & 245\end{array}$
Thermal expansion coefficients of the crystalline phase, obtained by molecular modelling, were taken from [31] (parameters are listed in Appendix D). Thermal expansion of the non-crystalline phase was assumed to be isotropic, i.e. characterised by only one parameter $\alpha^{\mathrm{a}}=7 \cdot 10^{-5} \mathrm{~K}^{-1}$, which is the measured CTE below $T_{\mathrm{g}}$. A comparison of the CTE at various crystallinities obtained using the composite inclusion model (with an isotropic distribution of the layered domains) and measured CTEs is shown in Fig. 9. The micromechanical model qualitatively predicts the evolution of the effective CTE of the isotropic material, although there is some quantitative deviation. For the isotropic material, the dependence of CTE on crystallinity is influenced by both the elastic and thermal properties of the phases. Elastic and thermal properties of the crystalline phase are obtained from molecular modelling and for the non-crystalline phase they are assumed to be isotropic and based on measurements on amorphous PET. Hence, the simulation is performed without any fitting parameters. In [18], it was already shown that parameters of unconstrained and constrained amorphous material differ, with the latter being anisotropic. In the model, anisotropic yielding was included by including the internal stresses. However, the elastic and thermal expansion properties are still isotropic. Deviations of the model from experimental data is therefore attributed to the anisotropy of the elastic and thermal properties of the non-crystalline phase, for which no experimental data is available.

A comparison of the model prediction of the CTE and the measurements for oriented film is shown in Table 2. The PET crystal has a negative CTE in the chain direction, i.e. the crystalline phase is contracting with increasing temperature in chain direction. Previous measurements show that MD is the dominant direction of the molecular chains in the crystalline domains of this PET film [18]. Therefore, for a high crystallinity of $50 \%$, it is expected that the CTE in TD is higher than in MD, which is also predicted by the model but not observed experimentally. Furthermore, in [32], the mechanical behaviour as well as thermal behaviour of biaxially oriented PET film were measured and it was found that the direction corresponding to the largest hardening modulus demonstrated the lowest linear thermal expansion. For the PET film studied here, TD corresponds to the largest hardening modulus and the CTE in TD has the lowest value. For uniaxially oriented films, modelling concepts based on a combination of crystalline and amorphous phases and tie molecules give a reasonable prediction of linear expansion [33], whereby the CTE in drawing direction decreases with draw ratio and the CTE normal to the drawing direction increases with draw ratio. This result also corresponds to the behaviour of the composite inclusion model studied here, where the lower CTE in MD is a result of the dominant chain orientation in MD. The explanation for the deviation observed here is most probably the anisotropy of the non-crystalline phase, in 


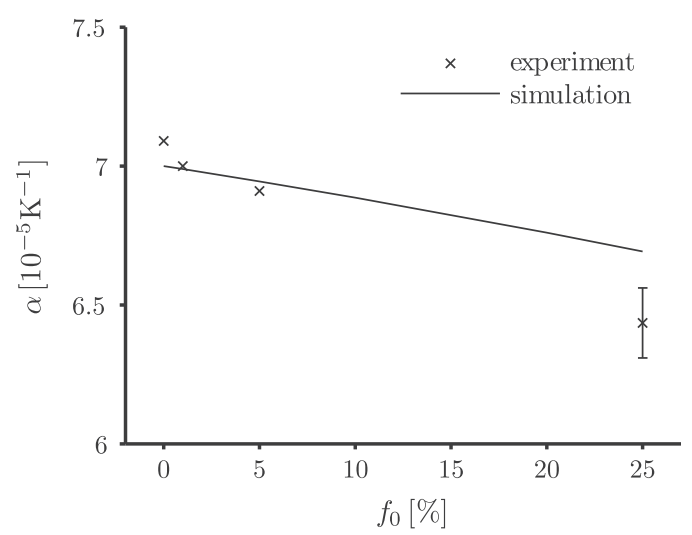

Fig. 9. Macroscopic CTE of isotropic PET vs. crystallinity. Both experimental data and model prediction are shown. The error bar indicates a 95\% confidence interval, where experimental scatter results from 4 measurements.

Table 2

Macroscopic CTE below $T_{\mathrm{g}}$ of oriented PET film in different directions.

\begin{tabular}{lll}
\hline Direction & TD & MD \\
\hline Measurement $\left(10^{-5} \mathrm{~K}\right)$ & 2.2 & 4.3 \\
Model $\left(10^{-5} \mathrm{~K}\right)$ & 5.4 & 3.0 \\
\hline
\end{tabular}

particular, an anisotropic CTE and elastic properties, resulting from the biaxial drawing process.

\subsection{Simulation of dimensional stability of oriented film}

A comparison of simulation results and measurements for the case when both reversible and irreversible processes contribute to strain during thermal loading is shown in Fig. 10, which is split into two parts: "heating" and "annealing". The model qualitatively predicts the experimentally observed behaviour in the entire temperature range, whereby the deformation rates are even quantitatively captured in the region up to $160{ }^{\circ} \mathrm{C}$. The fast change in deformation rate after $\sim 160{ }^{\circ} \mathrm{C}$ in the simulated results is due to stress relaxation in the first viscoelastic hardening mode, whereby only the second mode remains active. A more smooth transition, as observed in the experiment, can be achieved with a larger number of viscoelastic hardening modes with different pre-deformation ratios and different relaxation times. Both viscoelastic hardening modes are active at low temperatures. Therefore the film demonstrates shrinkage in MD and expansion in TD, i.e. corresponding to a uniaxial internal stress state. After relaxation of the first mode, the remaining biaxial internal stress state leads to shrinkage deformation in both directions, resulting in both MD and TD deformations below $-1 \%$. The exact mechanism of transformation of the internal stress state is discussed in Section 5.4. Due to a limited amount of viscoelastic modes (relaxation times), no subsequent deformation is observed during annealing at high temperatures. All modes already passed the relaxation process, which is not the case at lower temperatures, see Fig. 11.

The second case is fast heating with subsequent cooling. A comparison of simulation results and experimental data is shown in Fig. 12. As in the experiments, the line corresponding to the modelling results is based on strain values taken at $t=t_{\mathrm{e}}$ from simulations with an imposed temperature profile as in Fig. 1, with varying holding time (Fig. 12(a)) and varying temperature (Fig. 12(b)) and heating and cooling rates of $\dot{T}=17^{\circ} \mathrm{C} / \mathrm{s}$. The model qualitatively predicts the behaviour of the PET film. For an annealing temperature of $170{ }^{\circ} \mathrm{C}$, the model demonstrates fast deformation, reaching equilibrium faster than $10^{4} \mathrm{~s}$. In Fig. 12(b), qualitative deviations are observed at temperatures above $T=170^{\circ} \mathrm{C}$, where in the model, the internal biaxial stress state changes rapidly to a uniaxial stress state and the material starts to expand in MD. This can be remedied by using more relaxation modes. In the temperature regime corresponding to the application conditions (for flexible electronics manufacturing), up to $170^{\circ} \mathrm{C}$, the absolute deviation between the predicted and experimentally determined strain does not exceed $3.5 \cdot 10^{-3}$.

There is a small influence of the mismatch of the CTE prediction of the oriented film on the simulation of thermal deformation during heating, i.e. Figs. 10 and 11, where simultaneously reversible and irreversible effects are observed. For example at $150{ }^{\circ} \mathrm{C}$, with an accurate prediction of the CTE, the difference between model and experiment would have been larger in MD by an absolute value of strain of $1.2 \cdot 10^{-3}$ and smaller in TD by an absolute value of strain of $2.9 \cdot 10^{-3}$, whereas the experimental scatter of the absolute value of strain is up to $2.5 \cdot 10^{-3}$. Therefore, it can be concluded that simulation of the combined effect of reversible and irreversible thermal deformation is not qualitatively affected by the mismatch in CTE prediction, since the contribution of the irreversible deformation to the total strain is higher.

\subsection{Simulation of the long-term response}

As indicated in the introduction, the long-term behaviour of the material considered here was already predicted with the composite inclusion model in [18]. In the present article, an extension is made to the model, such that the pre-deformation (internal stress) of the non-crystalline phase in now modelled with two separate modes, describing the behaviour of the PET film at high temperatures. A simulation of the same creep conditions as in [18] with the extended model is shown in Fig. 13. As observed in the figure,
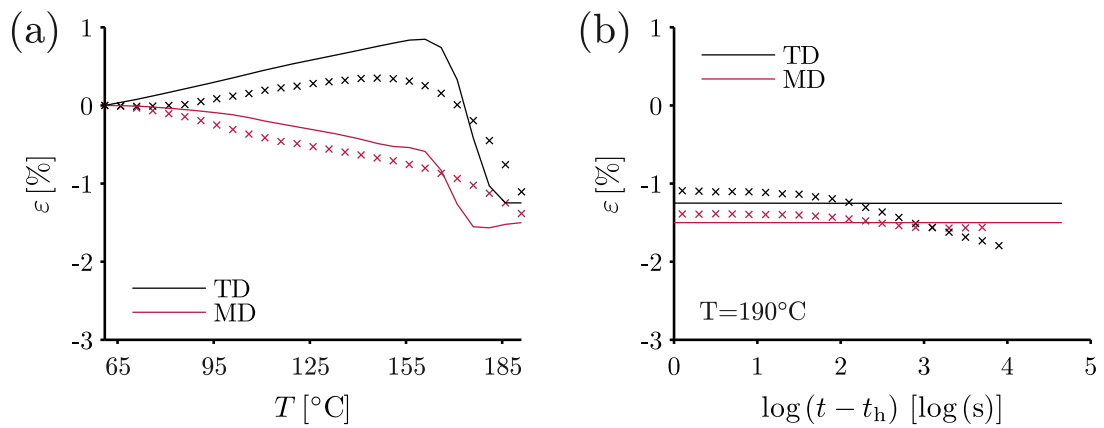

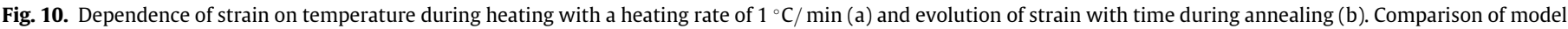
results (solid lines) and measurements (symbols) for MD and TD. 

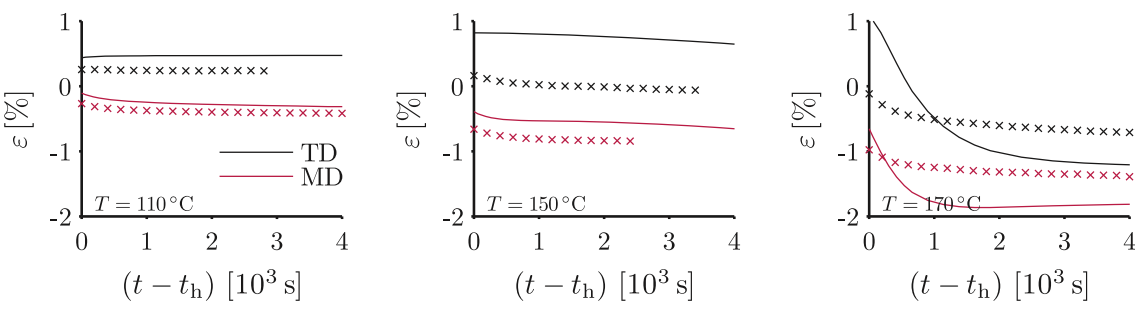

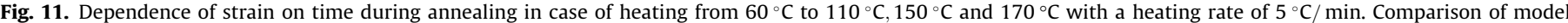
results (solid lines) and measurements (symbols) for MD and TD.
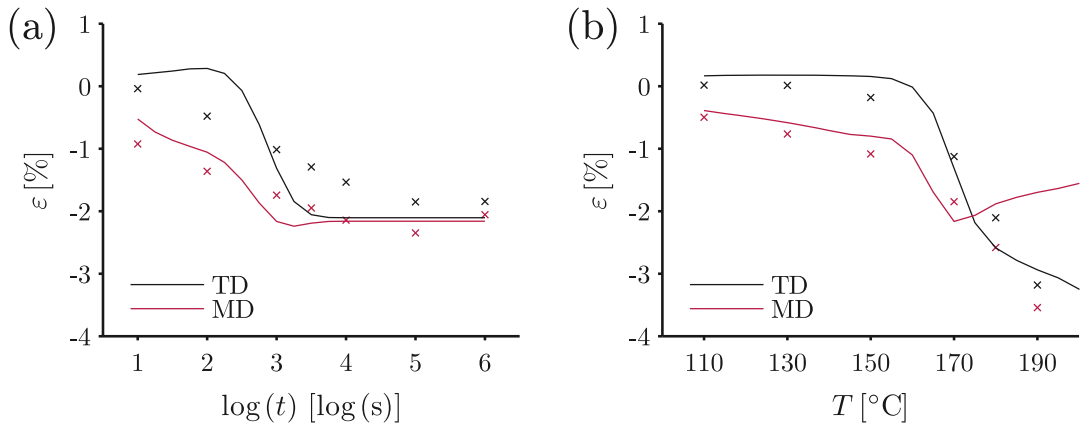

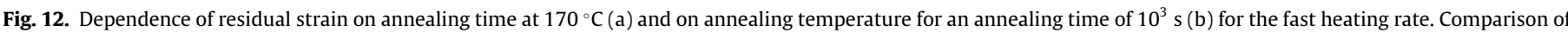
the model results (solid lines) and the measurements (symbols) for MD and TD.

the creep prediction of the model at $50{ }^{\circ} \mathrm{C}$ and a stress of $5 \mathrm{MPa}$ is not affected by the model extension, i.e. at lower temperatures the non-crystalline phase of the film demonstrates a uniaxial predeformation state (tensile state of the molecular network in MD). The deviation above $10^{9} \mathrm{~s}$ is a result of the asynchronous relaxation in the hardening viscoplastic elements due to a difference in the magnitude of the stress to which these elements are subjected. This deviation does not influence the applicability of the model.

\subsection{Local deformations}

As discussed in Section 4.1, the stress of the non-crystalline phase is split into two contributions: the intermolecular interactions and the molecular network. The latter is modelled with two viscoplastic hardening modes with different

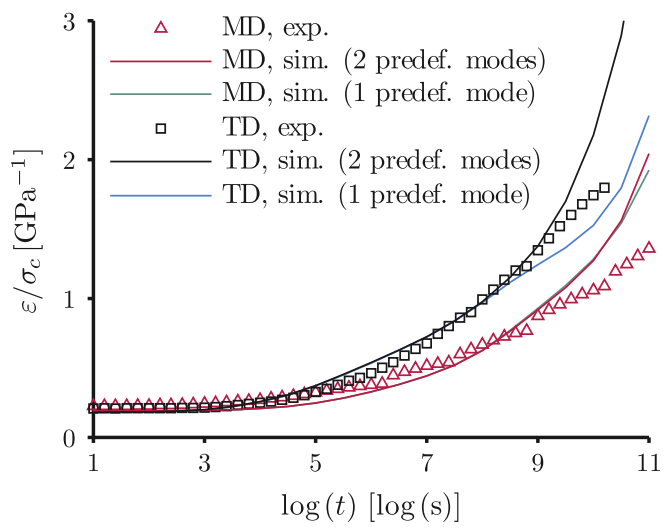

Fig. 13. Dependence of the creep compliance of oriented PET on time for different loading directions. Comparison of simulations (line) with measurements (symbols). Measurements are master curves constructed for $50{ }^{\circ} \mathrm{C}$, taken from [18]. Results corresponding to the case when one pre-deformation mode is used are also taken from [18]. pre-deformation, representing two different deformation modes. Mode 1 is pre-stretched in TD and mode 2 is pre-stretched in MD. To quantify plastic deformation in the modes, associated with relaxation of the molecular network $\boldsymbol{F}_{\mathrm{pr}_{j}}^{\mathrm{a}}$ (see Fig. 6(d)), the components of the inclusion-averaged plastic deformation gradient tensors are compared in Fig. 14(a). It can be observed that one of the processes is slower and has lower accumulated plastic deformation. The amount of plastic deformation is influenced by the amount of pre-deformation.

The internal stress state of the molecular network of the noncrystalline phase is shown in Fig. 14(b). The difference between MD and TD components of the volume-averaged tensor $\boldsymbol{\sigma}_{\mathrm{r}}^{\mathrm{a}}$, split into the contributions of two modes, is shown. Mode 1 is initially in a tensile state in TD and in a compressive state in MD, i.e. the in-plane stress state is close to uniaxial. Mode 2 provides an opposite initial stress state with a higher magnitude of stress. As observed in Fig. 14(b), the speed of stress relaxation of these modes is different. Therefore the total internal stress is transformed during relaxation from a state which is close to uniaxial (a positive MD stress component and a negative TD component) to a state which is close to biaxial (both MD and TD components are positive and approximately equal).

The deformation of the non-crystalline phase within the layered domain is strongly dependent on the orientation of the interface. The components of the deformation gradient tensor of the noncrystalline phase $\boldsymbol{F}^{\mathrm{a}}$ corresponding to the principal directions of the film depending on the orientation of the layered domains are shown in Fig. 15 (the corresponding macroscopic response is shown in Fig. 10). The selected temperatures correspond to moments when constant-rate thermal deformation is observed $\left(T=90^{\circ} \mathrm{C}\right)$, a change from expansion to shrinkage for TD $\left(T=160^{\circ} \mathrm{C}\right)$ and the end of the heating stage $\left(T=190{ }^{\circ} \mathrm{C}\right)$. Upon heating, the non-crystalline phase is contracting in MD and expanding in TD for domains with an interface normal oriented towards MD. The opposite effect is observed for domains, for which the interface normal is oriented towards TD. It was found that the molecular network stress hardly depends on the orientation of the 

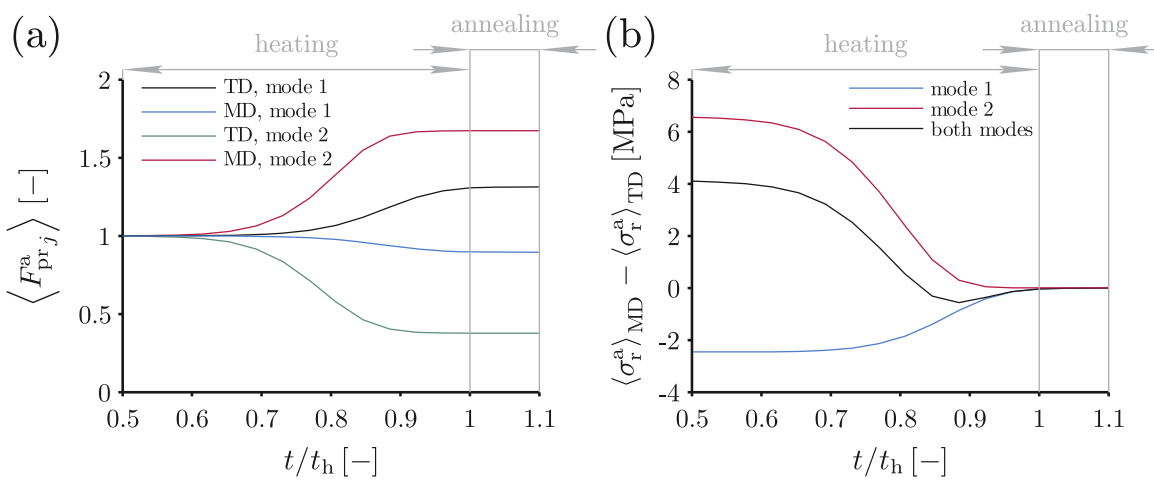

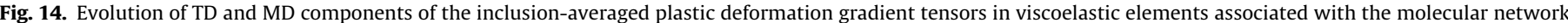

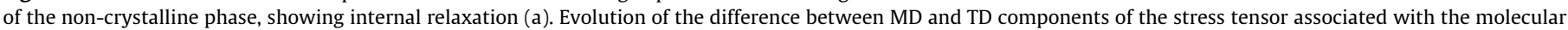

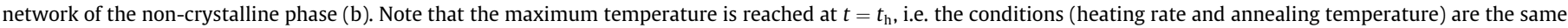
as for the results shown in Fig. 10.

$$
T=90^{\circ} \mathrm{C}
$$
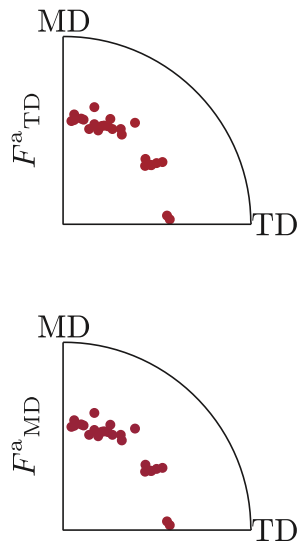

$T=160^{\circ} \mathrm{C}$
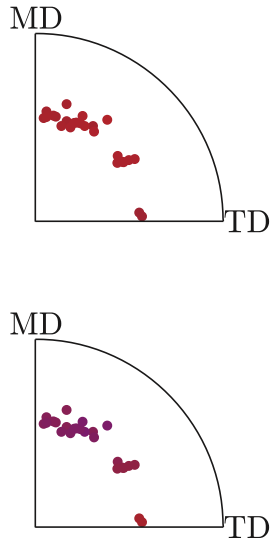

$T=190^{\circ} \mathrm{C}$

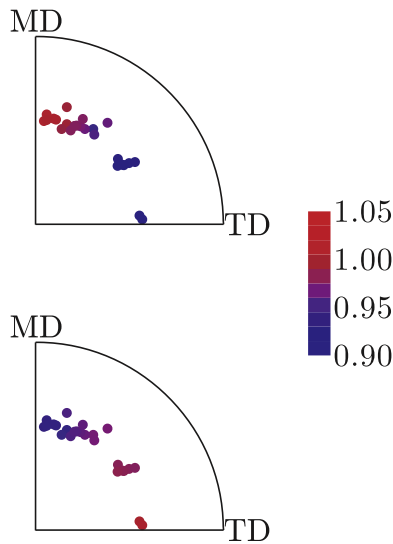

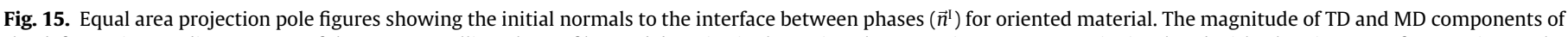

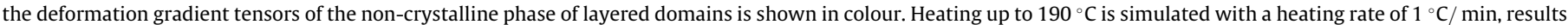
corresponding to two intermediate and final temperatures are shown.

layered domain. The maximum value of the variation in stress tensor components was found to be $0.35 \mathrm{MPa}$; for a comparison see Fig. 14(b).

The effect of the heating rate on the equivalent plastic deformation of the non-crystalline phase, defined as $\dot{\gamma}_{\mathrm{p}}^{\mathrm{a}}=\sqrt{2 \boldsymbol{D}_{\mathrm{p}_{1}}^{\mathrm{a}}: \boldsymbol{D}_{\mathrm{p}_{1}}^{\mathrm{a}}}$, is shown in Fig. 16(a). The relative change in plastic deformation $\Delta \gamma_{\mathrm{p}}^{\mathrm{a}}(t)=\gamma_{\mathrm{p}}^{\mathrm{a}}(t)-\gamma_{\mathrm{p}}^{\mathrm{a}}(0)$ is shown. Note that in case of slow heating, the magnitude of plastic deformation is lower, i.e. the amount of stress relaxation increases with decreasing heating rate. It was found that components of the volume-averaged stress tensor of the crystalline phase corresponding to TD and MD in the case of slow heating are qualitatively different than those for fast heating, see Fig. 16(b). The absolute value of the stress is slightly higher for the slow heating and is qualitatively different for MD, where it is compressive during fast heating and tensile during slow heating. When thermal expansion for both phases is disabled in the model (results not shown here), the stress in the crystalline phase is similar for both heating rates, i.e. the TD component increases and the MD component decreases during the initial part of the
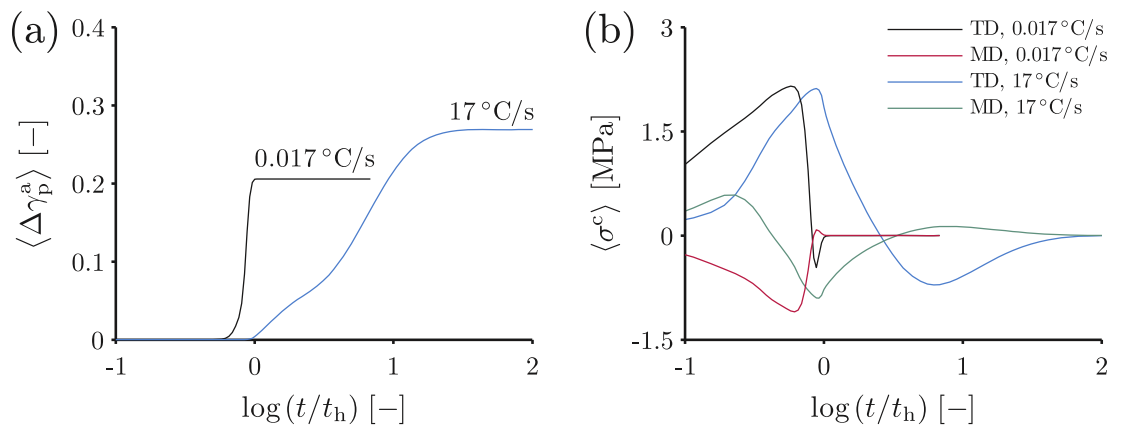

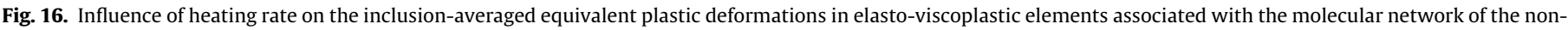
crystalline phase (a) and on the volume-averaged stress in the crystalline phase (b). In (b) the evolution of TD and MD tensor components is shown. 
heating. The initial qualitative difference for $\mathrm{MD}$ is due to the hydrostatic pressure resulting from a different thermal expansion of the phases. The compressive stresses in TD and tensile stresses in $\mathrm{MD}$ in the crystalline phase originate from the relaxation of the stress associated with the molecular network, see Fig. 14(b).

\section{Conclusions}

In this article, mechanisms of reversible and irreversible thermal deformation of a polymer film produced by biaxial stretching, have been investigated both experimentally and numerically using a micromechanical modelling approach taking into account the microstructure and different phases of the material. The investigated thermo-mechanical effects can be classified as shape memory effects, since the material is partially returning to its initial state prior to biaxial drawing. The measured thermo-mechanical film behaviour during heating was anisotropic with a qualitative change in thermal deformation around $160{ }^{\circ} \mathrm{C}$, after which significant thermal shrinkage is observed for both directions, while at lower temperatures thermal shrinkage is observed only for one of the principal directions of the film. Previous modelling work [18] indicated the necessity of taking into account the internal stress state of the non-crystalline phase for micromechanical modelling of the long-term response. In this article, the internal stress state is described by two deformation processes, each with its own internal stress state and thermal activation energy. At low temperatures, both processes act as one process as modelled in [18], such that the molecular network is in a tensile state in MD and in a compressive state in TD. With such an internal stress state of the material, the model quantitatively predicts the measured creep behaviour. At higher temperatures, due to a difference of activation energies, the processes separate and differently influence the material behaviour.

The two separate modes have pre-stretches in MD and TD and are activated at different temperatures. During biaxial drawing of PET film, molecules acquire mainly two types of orientations, in MD and in TD [34,35,3]. Thus pre-stretches of the viscoelastic hardening modes can be linked to deformations of the film, which occur in MD and TD drawing steps. Shrinkage in MD is observed at lower temperatures, which indicates that molecules that are oriented in MD are mechanically less constrained than ones oriented in TD.

It was found that at the microscopic scale, the deformation mechanisms do not significantly depend on the orientation of the interface during heating up to $160{ }^{\circ} \mathrm{C}$. The heating rate significantly influences not only the macroscopic behaviour but also the stress distribution at the local scale. During slow heating, the crystalline phase is subjected to a slightly higher equivalent stress than during fast heating, with a qualitative change in the MD component of the average crystalline stress tensor from compressive to tensile.

\section{Acknowledgements}

This research was carried out under project number M62.2.09331 in the framework of the Research Program of the Materials innovation institute (M2i) (www.m2i.nl). DuPont Teijin Films (www.dupontteijinfilms.com) and Holst Centre (www.holstcentre.com) are gratefully acknowledged for supplying the materials for this research. The authors would like to thank dr. MacKerron (DuPont Teijin Films) and dr. Smits (Holst Centre) for the extensive discussions on micromechanics of semicrystalline polymers.

\section{Appendix A. Composite inclusion model}

In this section, the equations representing the composite inclusion model are summarised. In addition to notations used in the article, a superscript " $k$ " is introduced to indicate that a tensor or scalar describes an inclusion with number $k$. The constitutive equations for each phase of the $N^{\mathrm{I}}$ inclusions specify the stress depending on the deformation gradient in the following way:

$\boldsymbol{\sigma}^{v k}(t)=\boldsymbol{\sigma}^{v k}\left(\boldsymbol{F}^{v k}, t^{*} \mid 0 \leqslant t^{*} \leqslant t\right) ; \quad k=\overline{1, N^{1}} ; \quad v=\mathrm{a}, \mathrm{c}$.

The material is modelled as a collection of layered domains, referred to as inclusions, see Fig. 4. Inclusion averaged quantities are obtained as:

$\boldsymbol{F}^{\mathrm{lk}}=\left(1-f_{0}\right) \boldsymbol{F}^{\mathrm{a} k}+f_{0} \boldsymbol{F}^{\mathrm{ck}}$

$\boldsymbol{\sigma}^{\mathrm{lk}}=\left(1-f^{k}\right) \boldsymbol{\sigma}^{\mathrm{a} k}+f^{k} \boldsymbol{\sigma}^{\mathrm{ck}}$

where the volume fraction of the crystalline phase, with $f_{0}$ the initial value, is given by:

$f^{k}=\frac{f_{0} J^{c k}}{\left(1-f_{0}\right) J^{a k}+f_{0} J^{c k}}$

with $J^{v k}=\operatorname{det}\left(\boldsymbol{F}^{v k}\right), v=\mathrm{a}, \mathrm{c}$. The orientation of the interface is given by two vectors $\vec{e}_{1}^{k k}$ and $\vec{e}_{2}^{\mid k}$ lying in the interface and its normal vector $\vec{e}_{3}^{I k}=\vec{n}^{I k}$. A subscript " 0 " indicates that quantities are taken in the initial configuration rather than in the current configuration.

In the inclusion, two layers are considered to be perfectly mechanically attached to each other. Therefore, equilibrium and compatibility conditions within each inclusion are enforced:

$$
\begin{aligned}
& \boldsymbol{\sigma}^{c k} \cdot \vec{e}_{3}^{1 k}=\boldsymbol{\sigma}^{\mathrm{ak}} \cdot \vec{e}_{3}^{1 k} ; \quad k=\overline{1, N^{1}} ; \\
& \boldsymbol{F}^{c k} \cdot \vec{e}_{n 0}^{1 k}=\boldsymbol{F}^{\mathrm{a} k} \cdot \vec{e}_{n 0}^{1 k} ; \quad k=\overline{1, N^{1}} ; \quad n=\{1,2\} .
\end{aligned}
$$

Various interaction laws between the inclusions can be defined. In this study, the $\hat{\boldsymbol{U}}$ interaction law [16] is used, for which an auxiliary deformation-like symmetric tensor $\hat{\boldsymbol{U}}$ is introduced as an unknown. A subscript " $M$ " indicates that quantities belong to the macroscopic scale. The following interinclusion interaction laws are imposed:

$\vec{e}_{m}^{1 k} \cdot \boldsymbol{\sigma}^{\mathrm{Il}} \cdot \vec{e}_{n}^{\mathrm{lk}}=\vec{e}_{m}^{\mathrm{lk}} \cdot \boldsymbol{\sigma}^{\mathrm{M}} \cdot \vec{e}_{n}^{\mathrm{Il}} ; \quad k=\overline{1, N^{\mathrm{I}}} ; \quad m, n=\{1,2\} ;$

$\boldsymbol{U}^{\mathrm{Ik}} \cdot \vec{e}_{30}^{\mathrm{Ik}}=\hat{\boldsymbol{U}} \cdot \vec{e}_{30}^{\mathrm{Ik}} ; \quad k=\overline{1, N^{\mathrm{l}}} ;$

$\boldsymbol{R}^{\mathrm{I} k}=\boldsymbol{R}^{\mathrm{M}} ; \quad k=\overline{1, N^{\mathrm{I}}}$

where the macroscopic Cauchy stress is determined by volume averaging:

$\boldsymbol{\sigma}^{\mathrm{M}}=\sum_{k=1}^{N^{\mathrm{I}}} f^{\mathrm{I} k} \boldsymbol{\sigma}^{\mathrm{I} k}$

and where $f^{\mathrm{lk}}=f_{0}^{\mathrm{lk}} J^{\mathrm{Ik}} / \mathrm{J}^{\mathrm{M}}$ is the volume fraction of the inclusion, $J^{\mathrm{M}}=\sum_{k=1}^{N^{1}} f_{0}^{\mathrm{lk}} J^{\mathrm{Ik}}$ is the macroscopic volume ratio, $f_{0}^{\mathrm{lk}}=1 / N^{\mathrm{I}}$ is the initial volume fraction of the inclusion and $J^{I k}=\operatorname{det}\left(\boldsymbol{F}^{\mathrm{Ik}}\right)$ is the volume change ratio of the inclusion. Volume averaging is also used to find the macroscopic right stretch tensor:

$\left(\frac{J^{\mathrm{M}}}{J_{\Sigma}}\right)^{\frac{1}{3}} \boldsymbol{U}^{\mathrm{M}}=\sum_{k=1}^{N^{\mathrm{l}}} f_{0}^{\mathrm{lk}} \boldsymbol{U}^{\mathrm{lk}}$

where $J_{\Sigma}=\operatorname{det}\left(\sum_{k=1}^{N^{1}} f_{0}^{\mathrm{lk}} \boldsymbol{F}^{\mathrm{Ik}}\right)$.

\section{Appendix B. Constitutive behaviour of crystalline phase}

In this section, the equations representing the constitutive behaviour of the crystalline phase are summarised. A multiplicative decomposition of the deformation gradient tensor is used, i.e. $\boldsymbol{F}^{\mathrm{c}}=\boldsymbol{F}_{\mathrm{e}}^{\mathrm{c}} \cdot \boldsymbol{F}_{\mathrm{t}}^{\mathrm{c}} \cdot \boldsymbol{F}_{\mathrm{p}}^{\mathrm{c}}$, with $\boldsymbol{F}_{\mathrm{t}}^{\mathrm{c}}$ being the deformation gradient tensor 
Table D.3

Components of the stiffness matrix and thermal expansion tensor of the PET crystal at $300 \mathrm{~K}$, from [31].

\begin{tabular}{|c|c|c|c|c|c|c|c|c|c|c|c|}
\hline $\begin{array}{l}\text { Parameter } \\
\text { Value (GPa) }\end{array}$ & $\begin{array}{l}C_{11}^{\mathrm{c}} \\
14.4\end{array}$ & $\begin{array}{l}C_{22}^{\mathrm{c}} \\
17.3\end{array}$ & $\begin{array}{l}C_{33}^{\mathrm{c}} \\
178.0\end{array}$ & $\begin{array}{l}C_{44}^{\mathrm{c}} \\
6.6\end{array}$ & $\begin{array}{l}C_{55}^{\mathrm{c}} \\
1.4\end{array}$ & $\begin{array}{l}C_{66}^{\mathrm{c}} \\
1.2\end{array}$ & $\begin{array}{l}C_{12}^{c} \\
6.4\end{array}$ & $\begin{array}{l}C_{13}^{\mathrm{c}} \\
3.4\end{array}$ & $\begin{array}{l}C_{23}^{\mathrm{c}} \\
9.5\end{array}$ & $\begin{array}{l}C_{14}^{c} \\
-2.2\end{array}$ & $\begin{array}{l}C_{24}^{c} \\
3.3\end{array}$ \\
\hline $\begin{array}{l}\text { Parameter } \\
\text { Value (GPa) }\end{array}$ & $\begin{array}{l}C_{34}^{\mathrm{c}} \\
3.8\end{array}$ & $\begin{array}{l}C_{15}^{\mathrm{c}} \\
-0.3\end{array}$ & $\begin{array}{l}C_{25}^{\mathrm{c}} \\
-0.5\end{array}$ & $\begin{array}{l}C_{35}^{\mathrm{c}} \\
-0.7\end{array}$ & $\begin{array}{l}C_{45}^{\mathrm{c}} \\
0.2\end{array}$ & $\begin{array}{l}C_{16}^{\mathrm{c}} \\
-1.8\end{array}$ & $\begin{array}{l}C_{26}^{\mathrm{c}} \\
0.5\end{array}$ & $\begin{array}{l}C_{36}^{\mathrm{c}} \\
-1.8\end{array}$ & $\begin{array}{l}C_{46}^{\mathrm{c}} \\
-0.4\end{array}$ & $\begin{array}{l}C_{56}^{\mathrm{c}} \\
0.0\end{array}$ & \\
\hline $\begin{array}{l}\text { Parameter } \\
\text { Value }\left(10^{-5} \mathrm{~K}^{-1}\right)\end{array}$ & $\begin{array}{l}\alpha_{11}^{\mathrm{c}} \\
11.4\end{array}$ & $\begin{array}{l}\alpha_{22}^{c} \\
4.12\end{array}$ & $\begin{array}{l}\alpha_{33}^{\mathrm{c}} \\
-1.07\end{array}$ & $\begin{array}{l}2 \alpha_{23}^{\mathrm{c}} \\
4.5\end{array}$ & $\begin{array}{l}2 \alpha_{13}^{c} \\
-1.38\end{array}$ & $\begin{array}{l}2 \alpha_{12}^{\mathrm{c}} \\
5.05\end{array}$ & & & & & \\
\hline
\end{tabular}

resulting from thermal expansion [28]. The elastic behaviour is modelled in the following way:

$\boldsymbol{S}_{\mathrm{e}}^{\mathrm{c}}={ }^{4} \mathcal{C}^{\mathrm{c}}: \boldsymbol{E}_{\mathrm{e}}^{\mathrm{c}}$,

where ${ }^{4} \mathcal{C}^{\mathrm{c}}$ is the elasticity tensor, $\boldsymbol{S}_{\mathrm{e}}^{\mathrm{c}}=J^{\mathrm{c}} \boldsymbol{F}_{\mathrm{e}}^{\mathrm{c}-1} \cdot \boldsymbol{\sigma}^{\mathrm{c}} \cdot \boldsymbol{F}_{\mathrm{e}}^{\mathrm{c}-\mathrm{T}}$ and $\boldsymbol{E}_{\mathrm{e}}^{\mathrm{c}}=\frac{1}{2}\left(\boldsymbol{F}_{\mathrm{e}}^{\mathrm{cT}} \cdot \boldsymbol{F}_{\mathrm{e}}^{\mathrm{c}}-\boldsymbol{I}\right)$. The velocity gradient tensor due to thermal expansion is [36]:

$\boldsymbol{L}_{\mathrm{t}}^{\mathrm{c}}=\dot{\boldsymbol{F}}_{\mathrm{t}}^{\mathrm{c}} \cdot \boldsymbol{F}_{\mathrm{t}}^{\mathrm{c}-1}=\boldsymbol{\alpha}^{\mathrm{c}} \dot{T}$,

where $\alpha^{\mathrm{c}}$ is a second-order tensor containing the thermal expansion coefficients. ${ }^{1}$ To complete the constitutive description, the viscoplastic behaviour is defined through the plastic velocity gradient tensor:

$\boldsymbol{L}_{\mathrm{p}}^{\mathrm{c}}=\dot{\boldsymbol{F}}_{\mathrm{p}}^{\mathrm{c}} \cdot \boldsymbol{F}_{\mathrm{p}}^{\mathrm{c}-1}=\sum_{\alpha=1}^{N^{\mathrm{s}}} \dot{\gamma}^{\alpha} \boldsymbol{P}_{0}^{\alpha}$,

where $\boldsymbol{P}_{0}^{\alpha}=\vec{s}_{0}^{\alpha} \vec{n}_{0}^{\alpha}$ is the non-symmetric Schmid tensor defined in the reference configuration. An Eyring flow rule is used for the plastic flow, i.e. the shear rate of slip system $\alpha$ is calculated in the following way:

$\dot{\gamma}^{\alpha}=\xi^{\alpha} \exp \left(\frac{\Delta U^{\alpha}}{R}\left(\frac{1}{T_{\mathrm{r}}}-\frac{1}{T}\right)\right) \sinh \frac{\tau^{\alpha}}{\tau_{0}^{\alpha}}$,

where $\Delta U^{\alpha}$ is the activation energy of the slip system, $T$ is the current temperature and $T_{\mathrm{r}}$ is a reference temperature. The shear stress $\tau^{\alpha}$ on slip system $\alpha$ is defined as:

$\tau^{\alpha}=\tau^{\mathrm{c}}: \boldsymbol{P}^{\alpha} ; \quad \boldsymbol{P}^{\alpha}=\boldsymbol{F}_{\mathrm{e}}^{\mathrm{c}} \cdot \boldsymbol{P}_{0}^{\alpha} \cdot \boldsymbol{F}_{\mathrm{e}}^{\mathrm{c}-1} ; \quad \tau^{\mathrm{c}}=J^{\mathrm{c}} \boldsymbol{\sigma}^{\mathrm{c}}$.

\section{Appendix C. Constitutive behaviour of amorphous phase}

In this section, the equations representing the constitutive behaviour of the non-crystalline phase are summarised. For each mode $i=\overline{1, N^{\mathrm{a}}}$, a multiplicative decomposition of the deformation gradient tensor is used (the plastic deformation is taken spin-free): $\boldsymbol{F}^{\mathrm{a}}=\boldsymbol{F}_{\mathrm{e}_{i}}^{\mathrm{a}} \cdot \boldsymbol{F}_{\mathrm{t}}^{\mathrm{a}} \cdot \boldsymbol{F}_{\mathrm{p}_{\mathrm{i}}}^{\mathrm{a}}$. The Cauchy stress tensor is split into a driving stress, which, in turn, is split into a hydrostatic part and a deviatoric part and a hardening stress:

$\boldsymbol{\sigma}^{\mathrm{a}}=\boldsymbol{\sigma}_{\mathrm{s}}^{\mathrm{ah}}+\boldsymbol{\sigma}_{\mathrm{s}}^{\mathrm{ad}}+\boldsymbol{\sigma}_{\mathrm{r}}^{\mathrm{a}}$.

The driving stress represents the contribution of the intermolecular interactions and is modelled with $N^{\mathrm{a}}$ viscoplastic modes, whereas the hardening stress represents the molecular network modelled with $N^{\mathrm{r}}$ viscoplastic modes:

$\boldsymbol{\sigma}_{\mathrm{s}}^{\mathrm{ah}}=K^{\mathrm{a}}\left(J_{\mathrm{e}}^{\mathrm{a}}-1\right) \boldsymbol{I} ; \quad \boldsymbol{\sigma}_{\mathrm{s}}^{\mathrm{ad}}=\sum_{i=1}^{N^{\mathrm{a}}} \boldsymbol{\sigma}_{\mathrm{s}_{i}}^{\mathrm{ad}}=\sum_{i=1}^{N^{\mathrm{a}}} G_{i}^{\mathrm{a}} \tilde{\boldsymbol{B}}_{\mathrm{e}_{i}}^{\mathrm{ad}} ; \quad \boldsymbol{\sigma}_{\mathrm{r}}^{\mathrm{a}}=\sum_{j=1}^{N^{\mathrm{r}}} G_{\mathrm{r} j} \tilde{\boldsymbol{B}}_{\mathrm{er}_{j}}^{\mathrm{ad}}$,

with $K^{\mathrm{a}}$ being the bulk modulus, $G_{i}^{\mathrm{a}}$ the shear moduli, $G_{\mathrm{rj}}$ the hardening moduli and $N^{\mathrm{r}}$ the number of viscoelastic hardening modes. The isochoric elastic Finger tensor of mode $i$ is calculated as:

\footnotetext{
${ }^{1}$ Eq. (B.2) is numerically integrated in the following way: $\boldsymbol{F}_{\mathrm{t}}^{\mathrm{c}}\left(t_{n+1}\right)=\exp \left(\Delta t \boldsymbol{\alpha}^{\mathrm{c}}\left(t_{n+1}\right) \dot{T}\left(t_{n+1}\right)\right) \cdot \boldsymbol{F}_{\mathrm{t}}^{\mathrm{c}}\left(t_{n}\right)$.
}

$\tilde{\boldsymbol{B}}_{\mathrm{e}_{i}}^{\mathrm{a}}=\int_{\mathrm{e}_{i}}^{\mathrm{a}-\frac{2}{3}} \boldsymbol{F}_{\mathrm{e}_{i}}^{\mathrm{a}} \cdot \boldsymbol{F}_{\mathrm{e}_{i}}^{\mathrm{aT}}$.

The elastic deformation gradient tensors of the modes corresponding to the molecular network, are determined from the following multiplicative decomposition:

$\boldsymbol{F}^{\mathrm{a}}=\boldsymbol{F}_{\mathrm{er}_{j}}^{\mathrm{a}} \cdot \boldsymbol{F}_{\mathrm{t}}^{\mathrm{a}} \cdot \boldsymbol{F}_{\mathrm{pr}_{j}}^{\mathrm{a}} \cdot \boldsymbol{F}_{\mathrm{d}_{j}}^{\mathrm{a}-1}, \quad j=\overline{1, N^{\mathrm{r}}}$,

where $\boldsymbol{F}_{\mathrm{d}_{j}}^{\mathrm{a}}$ is a deformation gradient tensor determining the initial pre-deformation of the network, such that $\operatorname{det}\left(\boldsymbol{F}_{\mathrm{d}_{j}}^{\mathrm{a}}\right)=1$. In this work the following form is adopted:

$\boldsymbol{F}_{\mathrm{d}_{j}}^{\mathrm{a}}=\lambda_{\mathrm{TD}_{j}} \vec{e}_{1} \vec{e}_{1}+\lambda_{\mathrm{MD}_{j}} \vec{e}_{2} \vec{e}_{2}+\frac{1}{\lambda_{\mathrm{TD}_{j}} \lambda_{\mathrm{MD}_{j}}} \vec{e}_{3} \vec{e}_{3}$,

where $\vec{e}_{2}$ corresponds to MD. The isochoric elastic Finger tensor of mode $j, \tilde{\boldsymbol{B}}_{\mathrm{er}_{j}}^{\mathrm{a}}$, is calculated in a similar way as in Eq. (C.3). The evolution of thermal expansion is according to:

$\boldsymbol{L}_{\mathrm{t}}^{\mathrm{c}}=\dot{\boldsymbol{F}}_{\mathrm{t}}^{\mathrm{c}} \cdot \boldsymbol{F}_{\mathrm{t}}^{\mathrm{c}-1}=\alpha^{\mathrm{a}} \dot{\boldsymbol{T}} \boldsymbol{I}$,

where $\alpha^{\mathrm{a}}$ is the scalar isotropic thermal expansion coefficient.

The viscoplastic behaviour is defined by the plastic part of the deformation rate:

$\boldsymbol{D}_{\mathrm{p}_{i}}^{\mathrm{a}}=\frac{1}{2}\left(\boldsymbol{L}_{\mathrm{p}_{i}}^{\mathrm{a}}+\boldsymbol{L}_{\mathrm{p}_{i}}^{\mathrm{aT}}\right)=\frac{\boldsymbol{\sigma}_{s_{i}}^{\mathrm{ad}}}{2 \eta_{i}}$

The viscosities $\eta_{i}$ for $i=\overline{1, N^{\mathrm{a}}}$ in Eq. (C.7) depend on the equivalent deviatoric driving stress $\tau$, temperature $T$, pressure $p^{\mathrm{a}}$, and thermodynamic state $S$, which here is taken to be 0 :

$$
\begin{aligned}
\eta_{i}= & \eta_{0 i} \exp \left(\frac{\Delta U}{R}\left(\frac{1}{T}-\frac{1}{T_{\mathrm{r}}}\right)\right) \frac{\tau / \tau_{0}}{\sinh \left(\tau / \tau_{0}\right)} \\
& \times \exp \left(\frac{\mu p^{\mathrm{a}}}{\tau_{0}}\right) \exp (S), \quad i=\overline{1, N^{\mathrm{a}}} ; \\
\tau= & \sqrt{\frac{1}{2} \boldsymbol{\sigma}_{\mathrm{s}}^{\mathrm{ad}}: \boldsymbol{\sigma}_{\mathrm{s}}^{\mathrm{ad}}} ; \quad \tau_{0}=\frac{k T}{V^{*}},
\end{aligned}
$$

where $R$ is the universal gas constant, $\Delta U$ the activation energy, $T_{\mathrm{r}}$ a reference temperature, $\boldsymbol{\sigma}_{\mathrm{s}}^{\text {ad }}$ is the overall deviatoric driving stress, $k$ is the Boltzmann constant and $V^{*}$ the activation volume. The plastic part of the deformation rate corresponding to the molecular network, $\boldsymbol{D}_{\mathrm{pr}}^{\mathrm{a}}$, is calculated in a similar way as in Eq. (C.7). The viscosities $\eta_{\mathrm{r} j}$ for hardening modes are only temperature dependent:

$\eta_{\mathrm{r} j}=\eta_{0 \mathrm{r} j} \exp \left(\frac{\Delta U_{\mathrm{r} j}}{R}\left(\frac{1}{T}-\frac{1}{T_{\mathrm{r}}}\right)\right), \quad j=\overline{1, N^{\mathrm{r}}}$.

Table D.4

Reference shear rates at different temperatures for the PET crystal.

\begin{tabular}{llll}
\hline Slip system & $(100)[001]$ & $(010)[001]$ & $(100)[010]$ \\
\hline$\xi^{\alpha}$ at $295 \mathrm{~K}\left(\mathrm{~s}^{-1}\right)$ & $10^{-16}$ & $10^{-80}$ & $10^{-30}$ \\
$\xi^{\alpha}$ at $463 \mathrm{~K}\left(\mathrm{~s}^{-1}\right)$ & $8 \cdot 10^{-6}$ & $7 \cdot 10^{-7}$ & $2 \cdot 10^{-2}$
\end{tabular}


Table D.5

Model parameters for PET, non-crystalline phase.

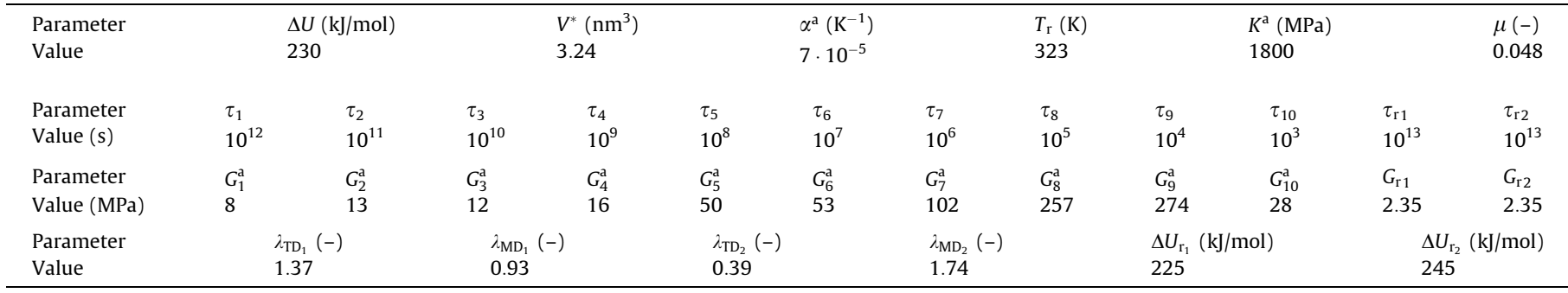

\section{Appendix D. Model parameters}

The stiffness matrix of the PET crystal is temperature dependent. In the model, values interpolated at a particular temperature are used [31]. Here only values at ambient temperature $(300 \mathrm{~K})$ are listed in Table D.3, where the Voigt notation $(11,22,33,23$, 31,12 ) is used (the coordinate system $\vec{i}_{1} \vec{i}_{2} \vec{i}_{3}$ is coupled to the crystal, see $[31,18])$. Parameters for the viscoplastic deformation for the crystalline phase are listed in Table D.4. For all slip systems, the reference shear stress is $\tau_{0}^{\alpha}=1.1 \mathrm{MPa}$.

For the non-crystalline phase, values of the parameters can be found in Table D.5. Relaxation times for the rejuvenated state are listed instead of viscosities $\tau=\eta / G^{\mathrm{a}}$, where the symbol $\tau$ is used for the relaxation time of the mode and not for the equivalent stress as in the model description.

\section{References}

[1] W.A. MacDonald, M.K. Looney, D. MacKerron, R. Eveson, R. Adam, K. Hashimoto, et al., J. Soc. Inform. Display 15 (12) (2007) 1075-1083, http:// dx.doi.org/10.1889/1.2825093.

[2] W.A. MacDonald, Polym. Int. 57 (5) (2008) 672-677, http://dx.doi.org/10.1002/ pi.2397.

[3] D.P. Jones, D.H. MacKerron, S.V. Norval, Plast. Rubber Compos. 42 (2) (2013) 66-74, http://dx.doi.org/10.1179/1743289812Y.0000000034.

[4] G. Schoukens, P. Samyn, S. Maddens, T. van Audenaerde, J. Appl. Polym. Sci. 87 (9) (2003), http://dx.doi.org/10.1002/app.11644.

[5] U. Goschel, Polymer 37 (18) (1996) 4049-4059, http://dx.doi.org/10.1016/ 0032-3861(96)00249-2.

[6] B. Haworth, Z.W. Dong, P. Davidson, Polym. Int. 32 (3) (1993) 325-335, http:// dx.doi.org/10.1002/pi.4990320317.

[7] V.B. Gupta, J. Radhakrishnan, S.K. Sett, Polymer 35 (12) (1994) 2560-2567, http://dx.doi.org/10.1016/0032-3861-(94)90379-4.

[8] M. Heuchel, T. Sauter, K. Kratz, A. Lendlein, J. Polym. Sci., Part B: Polym. Phys. 51 (8) (2013) 621-637, http://dx.doi.org/10.1002/polb.23251.

[9] P.M. Pakhomov, M.V. Shablygin, B.A. Tsaplin, S.A. Baranova, Z.P. Vysotskaya, Vysokomol. Soedin. A 25 (3) (1983) 572-577.

[10] J.L. Hu, Y. Zhu, H.H. Huang, J. Lu, Prog. Polym. Sci. 37 (12) (2012) 1720-1763, http://dx.doi.org/10.1016/j.progpolymsci.2012.06.001.

[11] Y.P. Liu, K. Gall, M.L. Dunn, A.R. Greenberg, J. Diani, Int. J. Plast 22 (2) (2006) 279-313, http://dx.doi.org/10.1016/j.ijplas.2005.03.004.

[12] H.J. Qi, T.D. Nguyen, F. Castroa, C.M. Yakacki, R. Shandas, J. Mech. Phys. Solids 56 (5) (2008) 1730-1751, http://dx.doi.org/10.1016/j.jmps.2007.12.002.

[13] G. Barot, I.J. Rao, K.R. Rajagopal, Int. J. Eng. Sci. 46 (4) (2008) 325-351, http:// dx.doi.org/10.1016/j.ijengsci.2007.11.008.

[14] B.J. Lee, A.S. Argon, D.M. Parks, S. Ahzi, Z. Bartczak, Polymer 34 (17) (1993) 3555-3575.
[15] B.J. Lee, D.M. Parks, S. Ahzi, J. Mech. Phys. Solids 41 (10) (1993) 1651-1687.

[16] J.A.W. van Dommelen, D.M. Parks, M.C. Boyce, W.A.M. Brekelmans, F.P.T. Baaijens, J. Mech. Phys. Solids 51 (3) (2003) 519-541.

[17] A. Sedighiamiri, L.E. Govaert, M.J.W. Kanters, J.A.W. van Dommelen, J. Polym. Sci., Part B: Polym. Phys. 50 (24) (2012) 1664-1679, http://dx.doi.org/10.1002 polb.23136.

[18] M. Poluektov, J.A.W. van Dommelen, L.E. Govaert, M.G.D. Geers, Modell. Simul Mater. Sci. Eng. 22 (2014) 055024.

[19] R.J. Asaro, A. Needleman, Acta Metall. 33 (6) (1985) 923-953, http://dx.doi.org/ 10.1016/0001-6160(85)90188-9.

[20] C.P. Buckley, D.C. Jones, Polymer 36 (17) (1995) 3301-3312, http://dx.doi.org/ 10.1016/0032-3861(95)99429-X.

[21] C.P. Buckley, P.J. Dooling, J. Harding, C. Ruiz, J. Mech. Phys. Solids 52 (10) (2004) 2355-2377, http://dx.doi.org/10.1016/j.jmps.2004.04.001.

[22] M.C. Boyce, D.M. Parks, A.S. Argon, Mech. Mater. 7 (1) (1988) 15-33, http:// dx.doi.org/10.1016/0167-6636(88)90003-8.

[23] E.M. Arruda, M.C. Boyce, Int. J. Plast 9 (6) (1993) 697-720, http://dx.doi.org/ 10.1016/0749-6419(93)90034-N.

[24] L.E. Govaert, P.H.M. Timmermans, W.A.M. Brekelmans, J. Eng. Mater. Technol. 122 (2) (2000) 177-185, http://dx.doi.org/10.1115/1.482784.

[25] E.T.J. Klompen, T.A.P. Engels, L.E. Govaert, H.E.H. Meijer, Macromolecules 38 (16) (2005) 6997-7008, http://dx.doi.org/10.1021/ma050498v.

[26] A. Sedighiamiri, D.J.A. Senden, D. Tranchida, L.E. Govaert, J.A.W. van Dommelen, Comput. Mater. Sci. 82 (2014) 415-426, http://dx.doi.org/ 10.1016/j.commatsci.2013.09.068.

[27] M. Poluektov, J.A.W. van Dommelen, L.E. Govaert, I. Yakimets, M.G.D. Geers, Modell. Simul. Mater. Sci. Eng. 21 (2013) 085015.

[28] J.A.W. van Dommelen, D.M. Parks, M.C. Boyce, W.A.M. Brekelmans, F.P.T Baaijens, Micromechanical modeling of the thermo-elasto-viscoplastic behavior of semi-crystalline polymers, in: Proceedings of the European Congress on Computational Methods in Applied Sciences and Engineering, Barcelona, 2000.

[29] T.A. Tervoort, R.J.M. Smit, W.A.M. Brekelmans, L.E. Govaert, Mech. TimeDependent Mater. 1 (1998) 269-291.

[30] L.C.A. van Breemen, T.A.P. Engels, E.T.J. Klompen, D.J.A. Senden, L.E. Govaert, J Polym. Sci., Part B: Polym. Phys. 50 (24) (2012) 1757-1771, http://dx.doi.org/ 10.1002/polb.23199.

[31] G.C. Rutledge, Macromolecules 30 (9) (1997) 2785-2791.

[32] B.F. Blumentritt, J. Appl. Polym. Sci. 23 (11) (1979), http://dx.doi.org/10.1002/ app.1979.070231106.

[33] C.L. Choy, M. Ito, R.S. Porter, J. Polym. Sci., Part B: Polym. Phys. 21 (8) (1983) 1427-1438, http://dx.doi.org/10.1002/pol.1983.180210813.

[34] C.J. Heffelfinger, R.L. Burton, J. Polym. Sci. 47 (0149) (1960) 289-306, http:// dx.doi.org/10.1002/pol.1960.1204714926.

[35] J. Kuusipalo, A.M. Savijarvi, S. Norval, M.J. Adlen, D.H. MacKerron, J. Mater. Sci. 39 (23) (2004) 6909-6919, http://dx.doi.org/10.1023/B:JMSC.0000047532. 34562.bc.

[36] F.T. Meissonnier, E.P. Busso, N.P. O’Dowd, Finite element implementation of a generalised non-local rate-dependent crystallographic formulation for finite strains, Int. J. Plast 17 (4) (2001) 601-640, http://dx.doi.org/10.1016/S07496419(00)00064-4. 